\title{
Comparison of Hand Therapy with or without Splinting Postfasciectomy for Dupuytren's Contracture: Systematic Review and Meta-Analysis
}

\author{
Mohammad Karam ${ }^{1, *}$ Narvair Kahlar ${ }^{1, *}$ Ahmad Abul ${ }^{1, *}$ Shafiq Rahman ${ }^{2}$ Richard Pinder ${ }^{2}$ \\ ${ }^{1}$ School of Medicine, University of Leeds, United Kingdom \\ 2 Department of Plastic Surgery, Hull University Teaching Hospitals \\ NHS Trust UK, United Kingdom \\ Address for correspondence Narvair Kahlar, Apartment 44, Leyland \\ House, 56 Mabgate, Leeds LS9 7EA, United Kingdom \\ (e-mail: kahlar13@gmail.com). \\ J Hand Microsurg 2022;14:308-314.
}

\begin{abstract}
Keywords

- hand therapy

- splinting

- Dupuytren's contracture

- fasciectomy

- postfasciectomy

This study aimed to compare the outcomes of hand therapy alone versus additional splinting post fasciectomy for Dupuytren's contracture patients. A systematic review and meta-analysis were conducted, and a search was performed identifying all relevant studies comparing the two groups. Primary outcome measures included Total active flexion and extension (TAF and TAE) and Disabilities of the Arm, Shoulder, and Hand (DASH) questionnaire. Secondary outcome measures included pain intensity, grip strength, and global perceived effect and patients' satisfaction. A random effects model was used for the analysis. Four RCTs were identified enrolling 295 patients. There were no significant differences between hand therapy and splintage groups in terms of all outcomes (both primary and secondary). Splintage offers no added functional benefit to hand therapy alone for post fasciectomy patients with Dupuytren's contracture, however, orthotic regimes may still be applied on an intention to treat basis in those patients who develop an extension deficit postoperatively.
\end{abstract}

\section{Introduction}

Dupuytren's disease is a common fibroproliferative condition involving the palmar fascia of the hand. ${ }^{1}$ Collagen proliferation leads to the formation of hard fibrous nodules and cords that cause progressive digital flexion. Without intervention, this can result in disabling contractures of the fingers. ${ }^{2}$ Surgical procedures such as fasciotomy or fasciectomy involve the division or excision (respectively) of diseased tissue to release the contractures. However, recurrence rates of up to $80 \%$ have been reported. ${ }^{3}$ Patients receive hand therapy as part of their rehabilitation postoperatively. ${ }^{4}$ Therapy commonly includes hand exercises with or without splinting, with proponents of each method demonstrating good outcomes. ${ }^{4}$

In order to optimize extension deficit correction and prevent postoperative contractures, many surgeons advo-

\footnotetext{
M.K., N.K., and A.A. contributed equally as first joint authors.

cate the practice of nocturnal extension splinting of the digits until the collagen has matured. ${ }^{4}$ Surveys of surgeons and other health care professionals identified that between 55 and $98 \%$ of respondents feel that there is a role for orthosis following surgery. ${ }^{5-7}$ However, some clinicians believe that splinting can be counterproductive, as the stress of the splint can lead to excessive proliferation of collagen and therefore can cause reccurence. ${ }^{8}$ The addition of an orthotic regime adds to the cost of treatment ${ }^{9}$ (both financially and the therapist's time with the patient).

Although many surgeons incorporate night splints into their management of Dupuytren's contractures, there are currently no definitive guidelines in relation to this. Hand therapy and splinting after surgery for Dupuytren's contractures have been compared in several randomized controlled trials and a nonrandomized study, as well as a systematic review. ${ }^{10-14}$ There is currently no meta-analysis that quantitatively compares their functional outcomes. We aimed to conduct a meta-analysis with the aim of helping to further

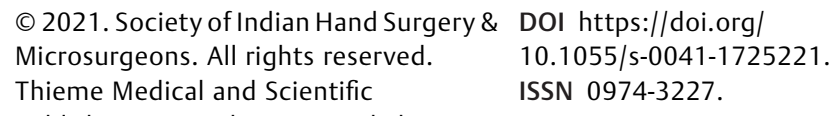


the evidence base to optimize postoperative outcomes as well as to effectively utilize available local resources.

\section{Materials and Methods}

A systematic review and meta-analysis were conducted as per the Preferred Reporting Items for Systematic Reviews and Meta-Analyses (PRISMA) guidelines. ${ }^{15}$

\section{Eligibility Criteria}

All prospective randomized and nonrandomized control trials as well as observational studies comparing hand therapy with splinting versus hand therapy alone postfasciectomy for Dupuytren's contracture were included. Splintage with hand therapy was the intervention group of interest, and hand therapy alone was the control group. All patients were included regardless of age or comorbidity status. Articles in which other treatment modalities were implemented other than fasciectomy or dermofasciectomy were excluded including collagenase injections and fasciotomies.

\section{Primary Outcomes}

The primary outcomes were mean improvement in total active flexion (TAF), total active extension (TAE), and the Disabilities of the Arm, Shoulder, and Hand (DASH) questionnaire scores from baseline under both treatment cohorts. Total active flexion is defined as the mean flexion in degrees per digit accounting for the metacarpophalangeal (MCP), proximal interphalangeal (PIP), and distal interphalangeal (DIP) joints. Similarly, Total active extension is the mean extension in degrees for each digit for the MCP, PIP, and DIP joints. The DASH questionnaire is a 30 -item questionnaire as a measurement of symptoms and physical function for patients with upper extremity disorders, which has been used broadly to assess postoperative outcomes for Dupuytren's contracture in numerous reports. ${ }^{16-18}$

\section{Secondary Outcomes}

The secondary outcomes included pain intensity, grip strength, global perceived effect, and patient satisfaction.

\section{Literature Search Strategy}

Three authors independently searched the following electronic databases: MEDLINE, EMBASE, EMCARE, CINAHL, and the Cochrane Central Register of Controlled Trials (CENTRAL). The last search was run on October 18, 2020. Thesaurus headings, search operators, and limits in each of the above databases were adapted accordingly. In addition, World Health Organization International Clinical Trials Registry (http://apps. who.int/trialsearch/), ClinicalTrials.gov (http://clinical- trials.gov/), and ISRCTN Register (http://www.isrctn. com/) were searched for details of ongoing and unpublished studies. No language restrictions were applied in our search strategies. The search terminologies included "Splint"," "orthos*," "Hand Therapy," "Hand Physio*," "Hand Physical Therapy," "Hand Rehab*," "Hand Physio*," "Occupational Therapy," "Hand Massage," and "Dupuytren's"." The bibliographic lists of relevant articles were also reviewed.

\section{Selection of Studies}

The title and abstract of articles identified from the literature searches were assessed independently by each author. The full texts of relevant reports and those selected that met the eligibility criteria for the review were retrieved. This included articles which had two groups of patients, an intervention and control group comparing splintage and hand therapy with hand therapy alone post-fasciectomy for Dupuytren's contracture. Articles not reported in English were excluded. Any discrepancies in study selection were resolved by discussion between the authors.

\section{Data Extraction and Management}

An electronic data extraction spreadsheet was created in line with Cochrane's data collection form for intervention reviews. ${ }^{19}$ The spreadsheet was pilot tested in randomly selected articles and adjusted accordingly. Our data extraction spreadsheet included study-related data (first author, year of publication, country of origin of the corresponding author, journal in which the study was published, study design, study size, clinical condition of the study participants, type of intervention, and comparison). Three authors cooperatively collected and recorded the results, and any disagreements were solved via discussion.

\section{Data Synthesis}

Data synthesis was conducted by using Review Manager 5.3 software. The analysis used was based on the random effect model. The results were reported in forest plots with 95\% confidence intervals (CIs). For continuous outcomes, the mean difference (MD) was calculated between the two groups. A positive MD for the TAF, TAE, or DASH score was in favor of the hand therapy group, a negative MD favored the splinting group, and a MD of 0 favored neither groups.

\section{Assessment of Heterogeneity}

Heterogeneity among the studies was assessed by using the Cochran Q test (Chi-square). Inconsistency was quantified by calculating $\mathrm{I}^{2}$ and interpreted by using the following guide: 0 to $25 \%$ was representative of low heterogeneity; 25 to $75 \%$ was indicative of moderate heterogeneity; and 75 to $100 \%$ was viewed as a high heterogeneity.

\section{Methodological Quality and Risk of Bias Assessment}

The Cochrane Collaboration's Tool was used to assess the quality of the RCTs included in the study (-Table 1). The tool assesses several domains in each paper namely sequence generation, allocation concealment, blinding of participants and personnel, blinding of outcome assessment, incomplete outcome data, selective outcome reporting and "other issues." The assessment of risk (low, high, or unclear) is given based on the authors judgement. For nonrandomized studies, the Newcastle-Ottawa scale ${ }^{20}$ was used to assess its quality which offers a star system for analysis (-Table 2). It offers a maximum score of nine stars across three domains including selection, comparability and exposure. A score of 9 is considered to be a low risk of bias, a score between 7 and 8 is considered medium 
310 Hand Therapy with or without Splinting Postfasciectomy Karam, Kahlar, and Abdul et al.

Table 1 Assessment of risk of bias of the randomized trials using the Cochrane Collaboration's Tool

\begin{tabular}{|c|c|c|c|}
\hline $\begin{array}{l}\text { Study } \\
\text { (Year) }\end{array}$ & Bias & $\begin{array}{l}\text { Study } \\
\text { judgement }\end{array}$ & Support for judgement \\
\hline \multirow[t]{7}{*}{$\begin{array}{l}\text { Collis et al } \\
(2013)^{11}\end{array}$} & Random sequence generation (selection bias) & Low risk & $\begin{array}{l}\text { Each participant selected a tag with a group } \\
\text { allocation concealed }\end{array}$ \\
\hline & Allocation concealment (selection bias) & Low risk & Group allocation concealed \\
\hline & Blinding of participants and personnel (performance bias) & Unclear risk & No information given \\
\hline & Blinding of outcome assessment (detection bias) & Unclear risk & No information given \\
\hline & Incomplete outcome data (attrition bias) & Low risk & No missing data \\
\hline & Selective reporting (reporting bias) & Low risk & All outcome data reported \\
\hline & Other bias & Low risk & Similar baseline characteristics in both groups \\
\hline \multirow{7}{*}{$\begin{array}{l}\text { Kemler et al } \\
(2012)^{12}\end{array}$} & Random sequence generation (selection bias) & Low risk & Table of random numbers used \\
\hline & Allocation concealment (selection bias) & Unclear risk & No information given \\
\hline & Blinding of participants and personnel (performance bias) & Unclear risk & No information given \\
\hline & Blinding of outcome assessment (detection bias) & Low risk & Blinded from outcome assessor and surgeon \\
\hline & Incomplete outcome data (attrition bias) & Low risk & No missing data \\
\hline & Selective reporting (reporting bias) & Low risk & All outcome data reported \\
\hline & Other bias & Low risk & Similar baseline characteristics in both groups \\
\hline \multirow{7}{*}{$\begin{array}{l}\text { Jerosch- } \\
\text { Herold et al } \\
(2012)^{13}\end{array}$} & Random sequence generation (selection bias) & Low risk & Central telephone randomization service \\
\hline & Allocation concealment (selection bias) & Unclear risk & No information given \\
\hline & Blinding of participants and personnel (performance bias) & High risk & $\begin{array}{l}\text { Neither the treatment therapist nor the } \\
\text { patients were blinded }\end{array}$ \\
\hline & Blinding of outcome assessment (detection bias) & Unclear risk & No information given \\
\hline & Incomplete outcome data (attrition bias) & Low risk & No missing data \\
\hline & Selective reporting (reporting bias) & Low risk & All outcome data reported \\
\hline & Other bias & Low risk & Similar baseline characteristics in both groups \\
\hline
\end{tabular}

Table 2 Newcastle-Ottawa scale to assess the quality of nonrandomized studies

\begin{tabular}{|l|l|l|l|}
\hline Study (Year) & Selection & Comparability & Exposure \\
\hline Glassey $(2001)^{14}$ & * $^{* *}$ & ${ }^{* *}$ & $* * *$ \\
\hline
\end{tabular}

Note: ${ }^{*}$ refers to the number of stars (see text for further details).

risk, and a score of 6 or lower is considered a high risk of bias.

\section{Results}

\section{Literature Search Results}

Through the online literature search and subsequent screening, the authors identified four studies which met the eligibility criteria (-Fig. 1 ).

The baseline characteristics of the included studies were summarized in - Table 3.

\section{Primary Outcomes}

\section{Range of Movement}

The improvement in the range of movement was assessed in terms of TAF and TAE gained in degrees postoperatively for all studies at a 3-month follow-up period. TAF (-Fig. 2) was reported in three studies enrolling 241 participants. This was the mean flexion in degrees per finger gained for MCP, PIP, and DIP joints. Overall, the three studies included a total of 256 fingers as some patients had multiple digits operated on. There was no significant difference seen in the mean difference analyses comparing the two groups ( $\mathrm{MD}=-11.28,95 \%$ CI: -45.91 to $23.35, p=0.52$ ). A high level of heterogeneity was found among the studies $\left(\mathrm{I}^{2}=90 \%, p<0.0001\right)$.

The mean total active extension ( - Fig. $\mathbf{3}$ ) gained in degrees per finger at 3 months postoperatively was reported in two studies enrolling 210 patients with a total of 215 digits. There was no statistically significant difference seen in the mean difference analyses comparing the two groups ( $\mathrm{MD}=-2.88$, $95 \% \mathrm{CI}:-11.43$ to $-5.68, p=0.51)$. A low level of heterogeneity was found among the studies $\left(\mathrm{I}^{2}=0 \%, p=0.78\right)$.

Disabilities of the Arm, Shoulder, and Hand Questionnaire The differences in the DASH questionnaire scores pre- and postfasciectomy at 3 months were reported by Collis ${ }^{11}$ and Jerosch-Herold. ${ }^{13}$ There was no significant difference seen in the mean difference analyses $(\mathrm{MD}=-2.15,95 \% \mathrm{CI}:-7.29$ to $-3.00, p=0.41)$. A low level of heterogeneity was found 


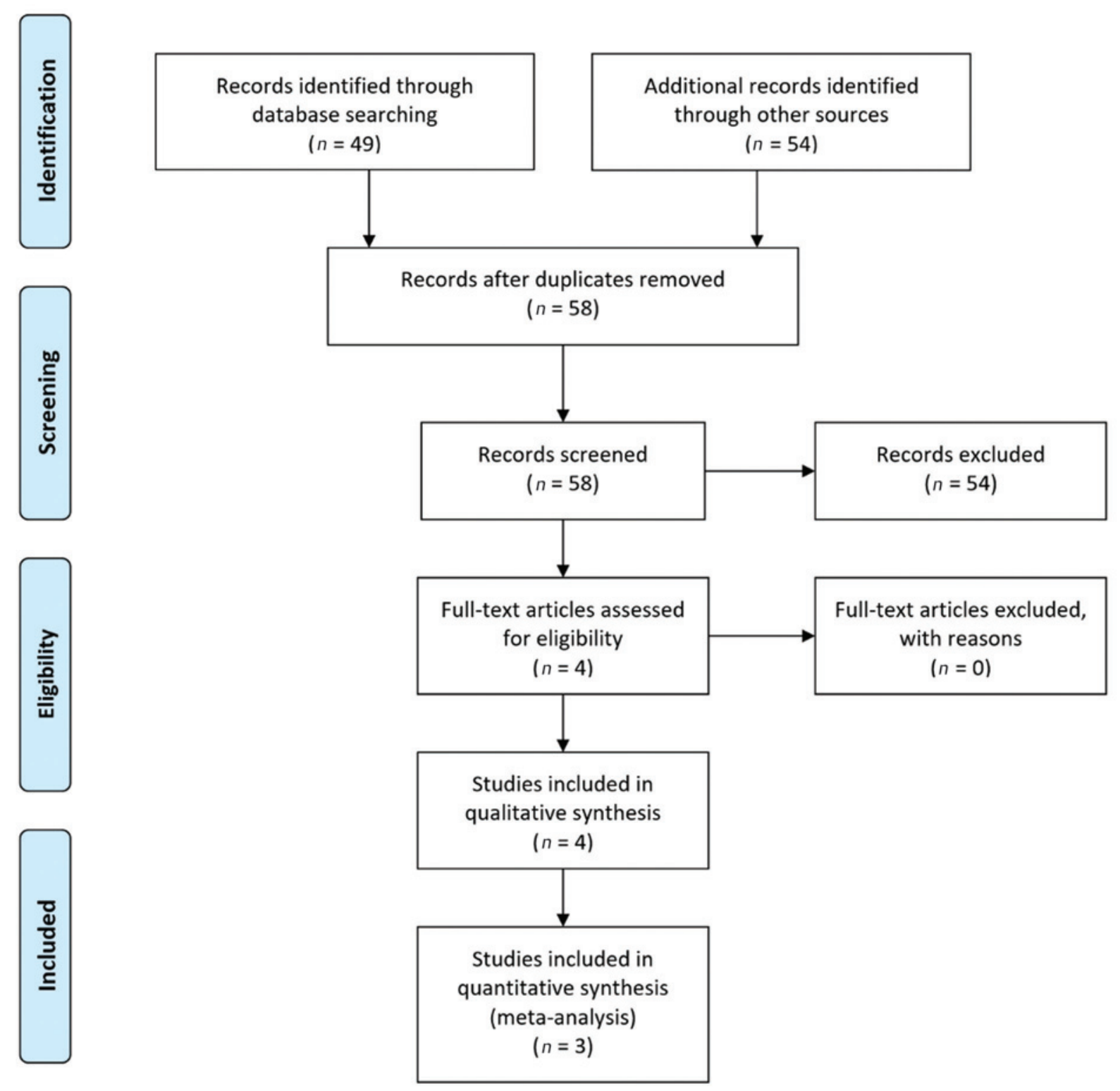

Fig. 1 PRISMA flow diagram, outlining the search and selection process for retrieved articles.

among the studies $\left(\mathrm{I}^{2}=0 \%, p=0.97\right)$. Collis reported a loss of three patients to follow up and Jeroch recorded two.

Glassey $^{14}$ also assessed hand function using the DASH questionnaire; however, only reported scores at 3 months therefore not allowing for a quantitative assessment of difference from baseline. According to Glassey, ${ }^{14}$ there was a significant advantage to hand function in the nonsplintage group ( $p=0.01$ ) at 3 months.

\section{Secondary Outcomes}

Intensity of Pain

Kemler ${ }^{12}$ and Glassey ${ }^{14}$ both reported no significant difference between the two groups in terms of intensity of pain with both studies using a $10-\mathrm{cm}$ visual analog scale (VAS) to assess intensity of pain. Kemler ${ }^{12}$ assessed pain intensity
6 weeks after surgery (VAS $=2.1 \pm 2.4$ [hand therapy alone] vs. $1.9 \pm 2.0$ [hand therapy with splint]; $p=0.7$ ), while Glassey ${ }^{14}$ analyzed pain intensity after 3 months (difference $=105.0 ; p=1.00$ ).

\section{Grip Strength}

According to Collis ${ }^{11}$ and Glassey, ${ }^{14}$ both studies assessed grip strength using a Jamar dynamometer and analyzed the results with a Mann-Whitney $U$ test. At 3 months posttreatment, Collis ${ }^{11}$ reported no significant difference between the no orthosis and orthosis groups in the right hand ( $33 \pm 13$ [hand therapy alone] vs. $27 \pm 12$ [hand therapy with splint]; $p=0.11$ ) and the left hand ( $30 \pm 13$ [hand therapy alone] vs. $25 \pm 11$ [hand therapy with splint]; $p=0.19$ ). Similarly, there was no significant difference reported by Glassey ${ }^{14}$ at 3 months (difference $=74.5 ; p=0.26$ ). 
312 Hand Therapy with or without Splinting Postfasciectomy Karam, Kahlar, and Abdul et al.

Table 3 Baseline Characteristics of the Included Studies.

\begin{tabular}{|c|c|c|c|c|c|c|c|}
\hline Study (Year) & Study design & $\begin{array}{l}\text { Total study } \\
\text { sample (hand } \\
\text { therapy alone: } \\
\text { splintage and } \\
\text { hand therapy) }\end{array}$ & $\begin{array}{l}\text { Sex } \\
\text { (male: } \\
\text { female) }\end{array}$ & $\begin{array}{l}\text { Mean age } \\
\text { (hand therapy } \\
\text { alone vs. } \\
\text { Splintage } \\
\text { and hand } \\
\text { therapy) }\end{array}$ & $\begin{array}{l}\text { Surgical } \\
\text { intervention }\end{array}$ & $\begin{array}{l}\text { Digits and } \\
\text { joints }\end{array}$ & $\begin{array}{l}\text { Criteria for "per } \\
\text { protocol" splintage } \\
\text { in hand therapy } \\
\text { only group }\end{array}$ \\
\hline $\begin{array}{l}\text { Collis et al }{ }^{11} \\
(2013)\end{array}$ & RCT & $56(30: 26)$ & $45: 11$ & $\begin{array}{l}67 \pm 9 \text { vs. } \\
68 \pm 8 y\end{array}$ & $\begin{array}{l}\text { Fasciectomy: } 50 \\
\text { Dermofasciectomy: } 6\end{array}$ & $\begin{array}{l}\text { Ring: } 22 \\
\text { Middle: } 13 \\
\text { Small: } 43 \\
\text { (MCP and } \\
\text { PIP joints) }\end{array}$ & $\begin{array}{l}\text { Extension loss } \\
\text { of greater than } \\
20 \text { degrees at } \\
\text { PIPJ or } 30 \text { degrees } \\
\text { at MCPJ compared } \\
\text { to first } \\
\text { postoperative } \\
\text { visit }(n=3)\end{array}$ \\
\hline $\begin{array}{l}\text { Kemler et al }{ }^{12} \\
(2012)\end{array}$ & RCT & $54(26: 28)$ & $46: 8$ & $\begin{array}{l}64 \pm 11 \text { vs. } \\
63 \pm 9 y\end{array}$ & Fasciectomy: 54 & NR & $\mathrm{Nil}$ \\
\hline $\begin{array}{l}\text { Jerosch- } \\
\text { Herold et al }{ }^{13} \\
\text { (2011) }\end{array}$ & $\mathrm{RCT}$ & $154(76: 75)$ & $120: 34$ & $\begin{array}{l}67.5 \pm 9.2 \text { vs. } \\
67.2 \pm 10.0 y\end{array}$ & $\begin{array}{l}\text { Fasciectomy: } 136 \\
\text { Dermofasciectomy: } \\
16\end{array}$ & $\begin{array}{l}\text { Index: } 8 \\
\text { Long: } 23 \\
\text { Ring: } 63 \\
\text { Small: } 109 \\
\text { (MCPS and } \\
\text { PIP joints) }\end{array}$ & $\begin{array}{l}\text { Extension loss } \\
\text { of greater than } \\
15 \text { degrees at } \\
\text { PIPJ or } 20 \text { degrees } \\
\text { at MCPJ at second } \\
\text { postoperative } \\
\text { visit }(n=13)\end{array}$ \\
\hline $\begin{array}{l}\text { Glassey }^{14} \\
(2001)\end{array}$ & $\begin{array}{l}\text { Retrospective } \\
\text { study }\end{array}$ & $31(10: 21)$ & $25: 6$ & $\begin{array}{l}58.5 \pm 13.15 \text { vs. } \\
68.76 \pm 7.62 \mathrm{y}\end{array}$ & Fasciectomy: 31 & $\begin{array}{l}\text { Fingers not } \\
\text { specified } \\
\text { (MCP, PIP, } \\
\text { and DIP } \\
\text { joints) }\end{array}$ & Not applicable \\
\hline
\end{tabular}

Abbreviations: DIP, distal interphalangeal joint; MCPJ, metacarpophalangeal joint; NR, not reported; PIP, proximal interphalangeal joint; PIPJ, proximal interphalangeal joint; RCT, randomized controlled trial.

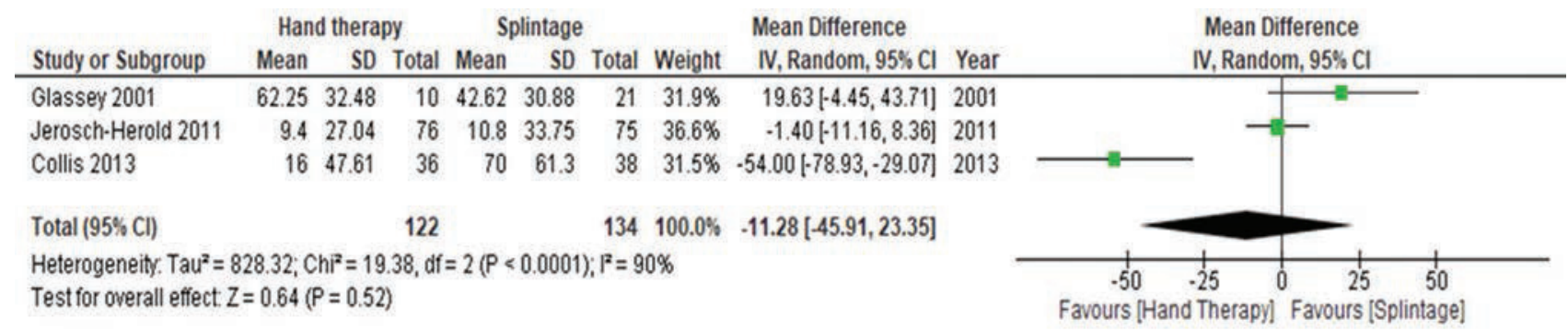

Fig. 2 Forest plot for hand therapy versus splinting (with hand therapy). Mean total active flexion gained in degrees per finger at 3 months postDupuytren's fasciectomy.

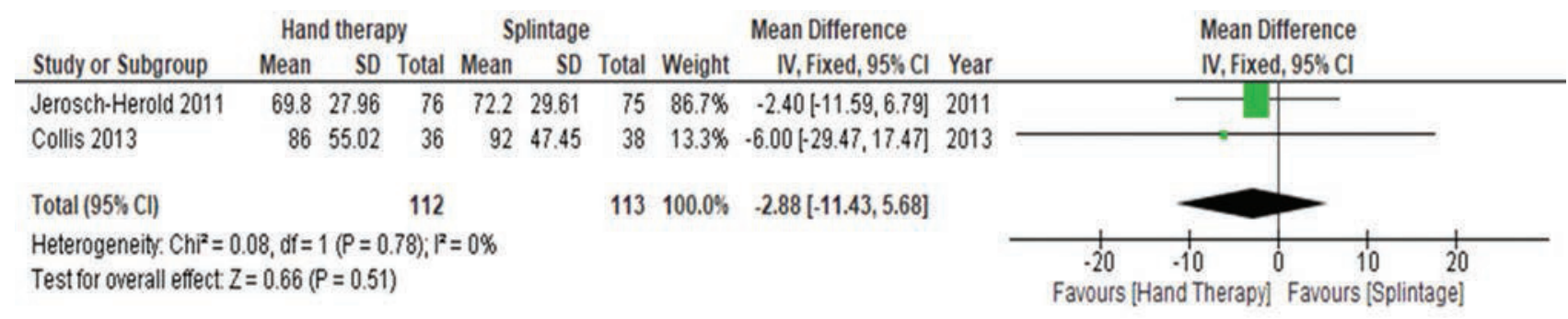

Fig. 3 Forest plot of hand therapy versus splinting (and hand therapy). Mean total active extension gained in degrees per finger at 3 months postoperatively. No significant difference identified with a mean difference analysis.

\section{Global Perceived Effect}

Global perceived effect is a numerical scale that is assessed by asking the patient to rate how much their condition has improved or worsened in a specified time. ${ }^{21}$ According to
Kemler, ${ }^{12}$ there was no significant difference associated with the mean global perceived effect between both groups 1 year after surgery (19 [hand therapy alone] vs. 18 [hand therapy with splint]; $p=0.5)$. 


\section{Patient Satisfaction}

Jerosch-Herold ${ }^{13}$ used a scale of 1 to 10 for assessing patient satisfaction in which there was no significant difference 6 months after surgery between both groups $(9.0 \pm 1.23$ [hand therapy alone] vs. $8.7 \pm 1.89$ [hand therapy with splint]; $p=0.254)$.

\section{Methodological Quality and Risk of Bias Assessment} The quality assessment of the RCTs ${ }^{11-13}$ included in the study was performed by using the Cochrane Collaboration's Tool as summarized in - Table 1. Newcastle-Ottawa Quality Assessment Scale was used for Glassey, ${ }^{14}$ a retrospective cohort study, showing high quality of selection, comparability, and exposure (-Table 2 ).

\section{Discussion}

Splints are commonly static, for ease of application and use, but they can be dynamic. ${ }^{22}$ Dynamic splinting incorporates a mechanical adaptation to allow movement of the digits while ensuring maintenance of the joints at end-range at rest. ${ }^{23}$ Static splinting involves using a dorsal or volar based splint that prevents movement of joints, ensuring stability, protection, and support in one particular position. ${ }^{24}$ In a review in 1992, static splits were deemed to be a superior option in patients with Dupuytren's contracture. ${ }^{7}$ However, Larson et al showed that dynamic splints could also improve the extension movement of the PIP joints in the long term. ${ }^{4}$ The literature is debated and inconclusive. The splints in all the studies examined in this review were static.

The results of this study show that the use of a splint offers no advantage in improving outcomes when compared with hand therapy alone. TAF ( - Fig. 2) and TAE (-Fig. 3) showed no improvement ( $p=0.52$ and $p=0.51$, respectively) in the splint and hand therapy group compared with the control group. DASH scores did not show any differences between

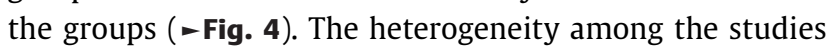
was low for all the outcomes $\left(\mathrm{I}^{2}=0 \%\right)$ apart from TAF which showed a high level $\left(\mathrm{I}^{2}=90 \%\right)$, based on the assessment as reported in Section 2. All the other outcomes, including pain, grip strength, global perceived effect, and satisfaction, showed no significant differences between the two groups.

It is, however, important to note that both Collis et al and Jerosch-Herold et al had an option in the nonsplinted group of intervening with the addition of a splint. This emphasizes that the hand therapist must be involved in the care of postfasciectomy patients and should see the patient over a period of time, rather than a single postoperative review (or not at all), in case intervention with a splint is deemed necessary. Jerosch-Herold et al, at the second postoperative visit, intervened with application of a splint if there was net loss of 15 degrees or more at the PIPJ and/or 20 degrees or more at MCPJ. Collis et al took a similar approach providing participants in the nonorthotic group with a splint if they lost extension $>20$ degrees at the PIPJ, or 30 degrees at MCPJ compared to the first postoperative measurement. It was not possible to assess this subgroup of patients in this metaanalysis as the data were not presented separately. However, an element of what is often termed "recurrence" of Dupuytren's Disease postoperatively will likely be to scarring and joint contracture rather than true recurrence of the disease. Hence, it would seem reasonable to take the approach of these authors and intervene with splintage when a net loss is noticed at either the MCPJ or PIPJ at the second postoperative visit, in order to combat digital contracture.

A recent review article by Pashmdarfard et al recommends the combination of orthosis and hand therapy in postfasciectomy treatment for Dupuytren's contracture to be the most effective choice and advocates consistent splint use for controlling pain and preventing contracture. ${ }^{10}$ However, the quantified outcome measures obtained in the current review suggests no difference to hand therapy alone. Splinting adds to the cost of treatment ${ }^{9}$ in addition to taking up clinic time from hand therapists (local department estimate $£ 5$ per splint, and 15 minutes of therapist's time per patient). Such resources should be therefore used judiciously in order to minimize financial constraints on health services and it would seem sensible to reserve splints for an intention to treat basis when there is a net loss of extension postoperatively.

A systematic method was used in this evaluation to provide a conclusion of the best available evidence and to explore the risk of bias of relevant trials. ${ }^{11-14}$ Based on the design and the populations studied, the three RCTs were standardized which makes the conclusions of this study robust from the best available evidence. However, the reported outcomes of the current review should be interpreted in the context of inherent limitations. Only four studies were identified consisting of 295 participants and the authors suggest more randomized trials to delineate further what the best rehabilitation protocol should be. In addition, outcomes should be reported more homogeneously over longer follow-up periods to enable a more robust analysis. Jerosch-Herold et $\mathrm{al}^{13}$ assessed extension at 6 months postoperatively, whereas the other authors

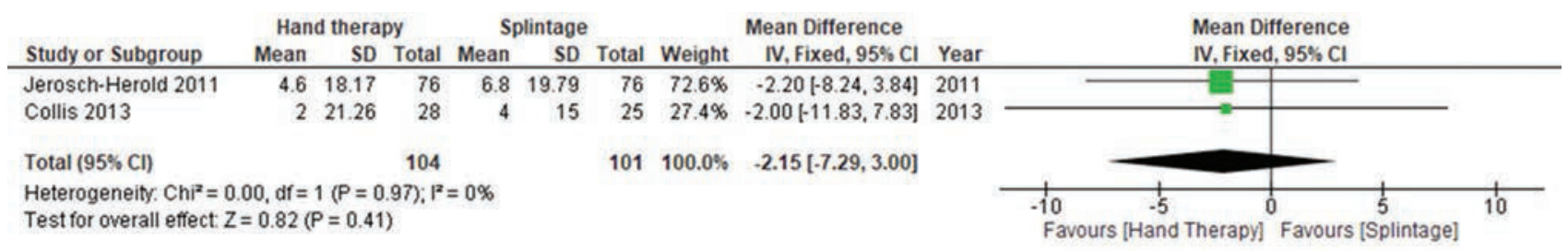

Fig. 4 Forest plot for hand therapy versus splinting (with hand therapy). DASH questionnaire. Quantitative analysis showing the mean difference in the DASH questionnaire reported by Collis (2013) and Jerosch-Herold (2011) from baseline to 3 months postfasciectomy. DASH, Disabilities of the Arm, Shoulder, and Hand. 
reported three monthly outcomes in the quantified variables for DASH, TAF as well as TAE. We would suggest that the timescale of reporting outcomes should be standardized at 6 months to ensure maintenance of extension. ${ }^{25}$

\section{Conclusion}

The findings of this review indicate that the addition of splintage adds no functional benefit when used in combination with hand therapy postfasciectomy for Dupuytren's contracture. However, close therapy-led follow-up of these patients is important, and there may be a role for the use of splinting in certain patients who appear to be deteriorating at after their initial postoperative review. The authors advocate judicious use of orthotic regimes as it adds to cost of treatment and should be reserved on an intention to treat basis only with development of an extension deficit postoperatively.

\section{Author Contributions}

M.K., N.K., and A.A. contributed equally as first joint authors in the acquisition, statistical analysis, and interpretation of data as well as drafting the manuscript. S.R. and R.P. were responsible for study concept, design, and supervision. All authors read and approved the final manuscript.

\section{Funding}

None.

\section{Conflict of Interest \\ None declared.}

\section{References}

1 Townley WA, Baker R, Sheppard N, Grobbelaar AO. Dupuytren's contracture unfolded. BMJ 2006;332(7538)397-400

2 Luck JV. Dupuytren's contracture; a new concept of the pathogenesis correlated with surgical management. J Bone Joint Surg Am 1959;41-A(04):635-664

3 Wurster-Hill DH, Brown F, Park JP, Gibson SH. Cytogenetic studies in Dupuytren contracture. Am J Hum Genet 1988;43(03): 285-292

4 Larson D, Jerosch-Herold C. Clinical effectiveness of post-operative splinting after surgical release of Dupuytren's contracture: a systematic review. BMC Musculoskelet Disord 2008;9(01):104

5 Abbott K, Denney J, Burke FD, McGrouther DA. A review of attitudes to splintage in Dupuytren's contracture. J Hand Surg [Br] 1987;12(03):326-328

6 Au-Yong ITH, Wildin CJ, Dias JJ, Page RE. A review of common practice in Dupuytren surgery. Tech Hand Up Extrem Surg 2005;9 (04):178-187

7 Mason R. The role of splintage in the post-operative management of Dupuytren's contracture. Br J Hand Ther 1992;1(04):6-12

8 Brandes G, Messina A, Reale E. The palmar fascia after treatment by the continuous extension technique for Dupuytren's contracture. J Hand Surg [Br] 1994;19(04):528-533
9 Haskett S, Backman C, Porter B, Goyert J, Palejko G. A crossover trial of custom-made and commercially available wrist splints in adults with inflammatory arthritis. Arthritis Rheum 2004;51 (05):792-799

10 Pashmdarfard M, Azad A, Amini M, Golabi G. The effect of splinting after Dupuytren's contracture operation: a systematic review. Iran Rehabil J 2019;17(04):297-304

11 Collis J, Collocott S, Hing W, Kelly E. The effect of night extension orthoses following surgical release of Dupuytren contracture: a single-center, randomized, controlled trial. J Hand Surg Am 2013; 38(07):1285-94.e2

12 Kemler MA, Houpt P, van der Horst CM. A pilot study assessing the effectiveness of postoperative splinting after limited fasciectomy for Dupuytren's disease. J Hand Surg Eur Vol 2012;37(08): 733-737

13 Jerosch-Herold C, Shepstone L, Chojnowski AJ, Larson D, Barrett E, Vaughan SP. Night-time splinting after fasciectomy or dermofasciectomy for Dupuytren's contracture: a pragmatic, multicentre, randomised controlled trial. BMC Musculoskelet Disord 2011;12(01):136

14 Glassey N. A study of the effect of night extension Splintage on post fasciectomy Dupuytren's patients. Br J Hand Ther 2001;6 (03):89-94

15 Moher D, Liberati A, Tetzlaff J, Altman DGPRISMA Group. Preferred reporting items for systematic reviews and meta-analyses: the PRISMA statement. Ann Intern Med 2009;151(04):264-269, W64

16 Ball C, Pratt AL, Nanchahal J. Optimal functional outcome measures for assessing treatment for Dupuytren's disease: a systematic review and recommendations for future practice. BMC Musculoskelet Disord 2013;14:131

17 van de Ven-Stevens LA, Graff MJ, Selles RW, et al. Instruments for assessment of impairments and activity limitations in patients with hand conditions: a European Delphi study. J Rehabil Med 2015;47(10):948-956

18 Engstrand C, Borén L, Liedberg GM. Evaluation of activity limitation and digital extension in Dupuytren's contracture three months after fasciectomy and hand therapy interventions. J Hand Ther 2009;22(01):21-26

19 Cochrane Collaboration. Data extraction forms. Accessed 2020 at: https://dplp.cochrane.org/data-extraction-forms

20 Wells GA, Shea B, O'Connell D, et al. The Newcastle-Ottawa Scale (NOS) for assessing the quality of nonrandomized studies in meta-analyses. Accessed 2020 at: www.ohri.ca/programs/ clinical_epidemiology/oxford.htm

21 Kamper SJ, Ostelo RW, Knol DL. Maher CG, de Vet HC, Hancock MJ. Global Perceived Effect scales provided reliable assessments of health transition in people with musculoskeletal disorders, but ratings are strongly influenced by current status. J Clin Epidemiol 2010;63(07):760-766

22 Pratt AL, Ball C. What are we measuring? A critique of range of motion methods currently in use for Dupuytren's disease and recommendations for practice. BMC Musculoskelet Disord 2016; 17(01):20

23 Finger E, Willis FB. Dynamic splinting for knee flexion contracture following total knee arthroplasty: a case report. Cases J 2008;1 (01):421

24 Schultz-Johnson K. Static progressive splinting. J Hand Ther 2002; 15(02):163-178

25 Kan. et al. Recurrence of Dupuytren's contracture: a consensusbased definition. 2017;12(05):e0164849 